\title{
ANÁLISE DO TESTE DE PERCUSSÃO EM FACHADA DE UMA EDIFICAÇÃO RESIDENCIAL NO MUNICÍPIO DE FORTALEZA-CE
}

\author{
SOARES TEIXEIRA FILHO, JOSÉ \\ Engenheiro Civil \\ SOARES ENGENHARIA \\ Ceará; Brasil \\ js-engenharia@hotmail.com
}

\author{
FERREIRA SOARES, KARYNE \\ Estudante de Engenharia Civil \\ SOARES ENGENHARIA \\ Ceará; Brasil \\ karynefs@hotmail.com
}

\section{RESUMO}

Durante muito tempo vem acontecendo inúmeros acidentes prediais no Brasil, dando foco na cidade de Fortaleza, que tem sido alvo de tais acidentes recentemente, muitas vezes custando os danos materiais e também a vida dos envolvidos. Com isso, o artigo em foco tem como objetivo principal realizar a análise do teste de percussão na fachada de uma edificação vertical residencial situado na cidade de Fortaleza - CE, para identificar as manifestações patológicas na fachada. A metodologia do estudo se deu através da descida de um funcionário em uma cadeirinha na fachada da edificação, para executar através da batida de um martelo de madeira contra o revestimento, a identificação e marcar com tinta a base de água, os revestimento com som cavo, fissurados e desplacados, como também, ausencia de rejunte. Palavras-chave: Inspeção Predial, teste de percussão, manifestações patológicas.

\section{ABSTRACT}

For a long time there have been countless building accidents in Brazil, focusing on the city of Fortaleza, which has been the target of such accidents recently, often costing material damages and also the lives of those involved. With this, the article in focus has as main objective to carry out the analysis of the percussion test on the facade of a vertical residential building located in the city of Fortaleza - CE, to identify the pathological manifestations on the facade. The methodology of the study was through the descent of an employee in a chair on the facade of the building, to execute through the tapping of a wooden hammer against the cladding, the identification and to mark with water-based paint, the cladding with cavo sound, cracked and cracked, as well as the absence of grout.

Keywords: Building inspection, percussion test, pathological manifestations.

\section{INTRODUÇÃO}

Os revestimentos de fachada de edifícios habitacionais exercem um papel importante para a garantir a durabilidade do edifício como um todo, além da sua principal função é proteger as vedações verticais contra agentes agressivos (MOSCOSO, 2013). Deste modo, o revestimento fica exposto a inúmeras solicitações deletérias, tais como variações térmicas, vento, umidade, ruído, chuva, incidência solar, carregamentos estático e dinâmico, impacto e peso próprio. Portanto, as fachadas das edificações, por estarem expostas às condições atmosféricas extremas naturais, representam uma das áreas mais danificadas ao longo do tempo, gerando incidências patológicas (BARBOSA, 2013).

As patologias nas fachadas atingem várias edificações, geralmente se dão pelo sistema de revestimento, resultante de defeitos que se originam nas paredes devido a diversos fatores que podem estar relacionados. As principais incidências patológicas percebidas em fachadas com revestimento cerâmico são, entre outras, desplacamento do revestimento, fissuras e trincas, eflorescência, manchamento, deterioração do revestimento e corrosão. Entre esses danos, o desplacamento cerâmico é o mais estudado, por reduzir a vida útil da edificação e ser um fator de risco para pedestres e carros que circulam nas proximidades dos edifícios (ULIANA et al, 2013).

Na construção civil, patologia é um termo que se refere ao estudo dos danos que ocorrem nas estruturas, que por se apresentar de diversas maneiras, recebe o nome de manifestações patológicas. A análise desses problemas é de suma importância, pois a sua existência é um indício de que algo está errado na edificação, podendo comprometer a segurança 
das pessoas (NEVES et al, 2017). Logo, constata-se que, para identificar as manifestações patológicas que incidem nas fachadas e minimizar os impactos nos revestimentos, são necessárias manutenções e inspeções periódicas, que têm a finalidade de detectar os problemas existentes, estudar as causas e avaliar o estado de deterioração do edifício. Nas cidades brasileiras, observam-se deficiências nas edificações existentes devido à ausência de planos estratégicos que norteiem a manutenção e conservação dos imóveis. Além da ausência de plano de manutenção, há a incidência dos acidentes prediais causados pela negligência de investimentos na área da manutenção preventiva e corretiva (PUJADAS, 2007).

Verifica-se a ocorrência de reiterados acidentes e incidentes prediais decorrentes de falhas na construção e/ou na manutenção predial, o que ensejou em mortes e prejuízos injustificáveis (BRANCO; NEVES, 2009). Durante muito tempo vem acontecendo inúmeros acidentes prediais no Brasil, como em Fortaleza, capital do Ceará, que tem sido alvo de tais acidentes recentemente, muitas vezes custando os danos materiais e também a vida dos envolvidos.

Em alguns países, manter o patrimônio imobiliário em boas condições de uso é uma questão cultural e rotineira. As experiências em cidades como Buenos Aires e Nova Iorque, onde têm sido aplicadas com sucesso leis que prevêem a inspeção e manutenção periódicas das edificações, garantiram a diminuição de acidentes com perdas humanas e a redução dos custos de intervenções corretivas (CAMPOS, 2012).

Em Fortaleza, surgiram medidas legais com o intuito de reduzir os acidentes prediais urbanos que acometem a segurança da população, através da Lei 9.913/12 que fala sobre inspeção predial, sendo que, somente em 2015, foi sancionada através do decreto 13.616. O Conselho Regional de Engenharia e Agronomia (CREA) descreve que inspeção representa a vistoria da edificação para determinar suas condições técnicas, funcionais e de conservação, visando direcionar o plano de manutenção (CREA/RN, 2013). Essa vistoria tem por finalidade verificar as condições de desempenho e determinar medidas corretivas e preventivas que se fizerem necessárias para a boa vida do imóvel e seus usuários (LIMA; OLIVEIRA; LOPES, 2016).

Nas últimas décadas, uma grande quantidade de publicações vem sendo produzidas no país sobre projeto e execução de edificações, contudo, a manutenção junto com a inspeção predial apenas recentemente tem sido foco de pesquisas acadêmicas. A implantação de um sistema de gestão da manutenção, com a avaliação frequente através de inspeções prediais periódicas, é o meio de se diminuir o colapso e deterioração precoce dos sistemas construtivos (KALIL et al, 2012).

A engenharia diagnóstica é um ramo da engenharia relativamente novo, se comparado com os demais, mas sua importância já é uma realidade em nosso meio. Na verdade, ela sempre esteve indiretamente incluída nos nossos conhecimentos e práticas, mas sua relevância fez com que seu estudo fosse especificamente designado. As ferramentas conhecidas da engenharia diagnóstica enriquecem a maneira como as edificações podem vir a ser observadas, assim como atividades necessárias ao bom funcionamento da edificação como um todo. A inspeção predial tem ocupado espaço importante como ferramenta na gestão dos ativos imobiliários, já que pode ser empregada na avaliação da manutenção e conservação das edificações (PUJADAS, 2007).

Diante o exposto, este artigo objetiva identificar em uma fachda com revestimento cerâmico, o desplacamento do revestimento, fissuras e rechaduras, som cavo e ausencia de rejunte.

\subsection{Acidentes prediais}

Com a construção dos seus abrigamentos, o homem vem tentando esclarecer a razão dos acidentes que os atingem. Quando se constrói, há o objetivo do interesse em atender o desempenho e funcionalidade pelo tempo em que a construção foi projetada, e quando isso não ocorre o homem é inspirado a investigar explicações (MUNHOZ DE MOURA, 2017).

No Brasil, os acidentes prediais ocorridos são causados em sua maioria por anomalias e falhas, quer de projetos, quer construtiva ou de manutenção, indicam uma inevitável conscientização maior dos condôminos das edificações com os cuidados técnicos indispensáveis à boa segurança e uso de edificações (GOMIDE et al, 2006).

Quando ocorrem tragédias e acidentes prediais, principalmente quando divulgado pela imprensa, há o clamor público gerando a cobrança do governo por condutas para evitar novas eventualidades. Em seguida, os políticos proporcionam medidas legislativas visando evitar novos acidentes, obrigando inspeções por parte dos órgãos responsáveis ou promulgando leis de inspeção de edificações (OLIVEIRA, 2009). 
A inspeção predial é uma ferramenta que identifica a tempo problemas na edificação, garantindo segurança aos seus usuários. Leis sobre manutenção predial, que obriguem a realização de inspeções em edificações públicas e privadas, surgiram em algumas cidades do Brasil, como Porto Alegre. A prefeitura municipal de Porto Alegre outorgou a lei $n^{\circ}$ 6.323, em 30 de dezembro de 1988, complementada pelo Decreto $\mathrm{n}^{\text {o }} 9.425$ de 29 de abril de 1989 que determina métodos para a conservação de elementos nas fachadas dos prédios, sendo outorgada logo após alguns acidentes fatais na região. Após essa data, os estudos sobre o tema de inspeção predial foram aperfeiçoados, novas técnicas foram ingressadas e algumas adaptações surgiram com o objetivo de adequar o assunto às necessidades do mercado atual (SILVA, 2016).

Saindo do Brasil, em Buenos Aires, na Argentina, a lei de inspeção surgiu em 1999, logo após dois acidentes que resultaram o óbito de pedestres. Esta lei exige que os proprietários realizem vistorias, com intervalo proporcional à idade da construção, em fachadas, como também a inspeção de elementos que não façam parte da estrutura da edificação, como toldos e letreiros (OLIVEIRA, 2008).

Problemas de elementos nas fachadas das edificações causando acidentes com pedestres já ocorriam há um bom tempo, como exemplo na cidade de Chicago, Estados Unidos, com a morte de um pedestre em 1974, ferido pela queda de um tijolo da fachada de um dos muitos edifícios da região central. Vale ressaltar que queda de elementos em fachada não é um problema localizado, pois tijolos caem das fachadas em algum lugar nos Estados Unidos a cada três semanas, muitas vezes causando graves conseqüências à população (OLIVEIRA, 2008). Outro retrato desta situação ocorreu na cidade de Columbus, em 1984, o pedestre atingido foi um vereador, Ben Espy, que teve parte de sua perna amputada devido à queda de um pedaço de concreto que se desprendeu da fachada de um condomínio (GRIMM, 2000).

Em dezembro de 1997, em Nova Iorque, ocorreu uma queda de tijolos provenientes do $39^{\circ}$ andar de um edifício da ilha de Manhattan, ferindo dois pedestres e fechando uma das principais avenidas da cidade, numa época de grande movimento no comércio local. A fachada lateral da qual desprendeu os tijolos, não havia sido vistoriada e inspecionada, pois a lei apenas exigia inspeção das fachadas localizadas sobre passeios públicos. Contudo, a lei em vigor sofreu modificações até os adias atuais, e a inspeção abrange todas as fachadas de edificações com mais de 6 pavimentos com exceção com distâncias inferior a 30 centímetros das paredes externas do edifício adjacente (OLIVEIRA, 2008).

Contudo, os acidentes ocorridos na construção civil tiveram várias vítimas fatais, que poderiam ter sido evitadas quando da manutenção predial fosse realizada, e até mesmo minimizados os impactos. Os meios de comunicação registram vários casos de acidentes prediais, porém só alguns mais graves são tratados pela mídia, vindo a ocorrer inúmeros outros que a mídia não trata, e muitos que não constam em qualquer documento. Entretanto, a ocorrência da inspeção e manutenção predial preventiva e adequada, poderiam evitar e até mesmo diminuir possíveis desabamentos ou acidentes, decorrentes do agravamento das falhas ou anomalias (ALVES, 2018).

\subsection{História da inspeção predial no Brasil}

A construção civil apresentou um aumento nos últimos anos, acarretando acréscimo no número de obras em execução (BRITO, 2017). Com o passar do tempo, diversas cidades brasileiras foram motivadas devido a situações indesejáveis em edificações, como acidentes prediais, aprovando leis para tornar a atividade de inspeção predial obrigatória.

A inspeção predial faz parte do ramo da engenharia diagnóstica e surgiu com a finalidade de auxiliar e orientar os usuários de uma edificação sobre a qualidade de seu uso e manutenção (MATTOS JÚNIOR et al, 2017).

No Brasil, o assunto surgiu com o um trabalho técnico apresentado no X Congresso Brasileiro de Avaliações e Perícias de Engenharia (COBREAP), em Porto Alegre, no ano de 1999, de autoria do primeiro autor sobre inspeção predial, o engenheiro Tito Lívio Ferreira Gomide. Com o passar do tempo, estimulados por ocorrências insatisfatórias, diversas cidades brasileiras, primeiramente a capital gaúcha Porto Alegre, aprovaram leis para tornar a atividade de inspeção predial obrigatória (NEVES, 2009). Com o intuito de padronizar a inspeção predial, no ano de 2001, o Instituto Brasileiro de Avaliações e Perícias de Engenharia (IBAPE) de São Paulo lançou a primeira norma técnica sobre o tema, proporcionando ao profissional responsável pela elaboração do serviço, um balizador das atividades a serem executadas. Desde o lançamento, a norma passou por diversas atualizações, sendo a última delas, realizada no ano de 2011, coordenada pelo engenheiro Vanderley Jacob Júnior (NEVES, 2009).

O desenvolvimento da inspeção predial estimulou outros trabalhos técnicos, como as vistorias de vizinhança, auditorias de projetos, vistorias de conclusão de obra e perícias em produtos e serviços da construção civil, tudo visando a melhoria da segurança e qualidade construtiva. Em países desenvolvidos, a inspeção predial é uma prática rotineira, 
podendo ser visto em alguns edifícios o certificado de inspeção afixado no quadro de avisos (MATTOS JÚNIOR et al, 2017).

A inspeção predial é de fundamental importância e está sendo bastante discutida atualmente diante da ocorrência vários acidentes relacionados a falta de manutenções nas edificações. Dessa forma, em prol da redução de acidentes prediais urbanos, que, assim como outros fatores em uma cidade, acometem a segurança da população, a Lei 9.913/12 de inspeção predial foi criada com o intuito de diminuir esses acidentes prediais em Fortaleza, capital do Ceará, através de vistorias e manutenções periódicas possibilitando classificar as anomalias identificadas quanto a rapidez com a qual elas necessitam ser sanadas, além de fornecer recomendações técnicas a respeito das ações corretivas.

\subsection{Teste de percussão de fachada}

Através da inspeção predial, pode ser requerido e indicado a elaboração de um laudo de percussão, este vai constar o seu objetivo geral e específico do estudo abordado. Com o teste de percussão, é possível mapear as desconformidades do sistema de vedação da fachada.

As manifestações patológicas em fachadas, que afetam tantas edificações na cidade de Fortaleza, podem ser provenientes da qualidade do material utilizado, durabilidade do produto, execução, condições de trabalho e falta de uma adequada manutenção.

O teste inicia com a ancoragem e fixação da linha de vida do balancim individual do tipo "cadeirinha", logo após, é realizado a descida da cobertura ao térreo através de profissional habilitado e capacitado, garantindo assim condições seguras de trabalho. Após isso, o colaborador vai realizar o teste de percussão com o auxílio de um martelo de madeira em toda a extensão da fachada, mapeando os pontos que estão com som cavo, desplacado, fissurado, rachado, com ausência de rejunte. Vale salientar que, durante o teste, são atribuídos símbolos para melhor identificação do problema.

\section{METODOLOGIA}

Para o desenvolvimento do artigo, seu conteúdo foi dividido de tal forma que seja possível especificar e designar em uma ordem lógica, clara e objetiva fazendo pesquisas e condutas necessárias para produzir um estudo de caso, gerando resultados reais sobre o assunto citado.

Quanto aos aspectos metodológicos empregados para o desenvolvimento do vertente trabalho, se buscou informações, por meio de pesquisa bibliográfica, apresentando um grande volume de informação recebida por livros, páginas de internet, normas técnicas referentes ao tema, artigos publicados, teses, trabalho de conclusão de graduação, dissertações de mestrado e pós-graduação, apresentações em congresso e outros materiais, sendo interpretada a revisão bibliográfica da melhor maneira possível.

Quanto aos fins, a pesquisa classifica-se como exploratória, visto que busca aprimorar ideias, estabelecendo bases que podem gerar futuras pesquisas. Quanto à abordagem, a pesquisa é um estudo de caso, já que o estudo foi um método de pesquisa que utilizou dados qualitativos, quantitativos e coletados a partir de eventos reais na construção civil. Em relação ao resultado, como possui a finalidade de ampliar o conhecimento sobre a temática, a pesquisa é pura (GIL, 2007).

Quanto a pesquisa em campo, foram realizadas vistorias numa edificação vertical residencial da cidade de Fortaleza$\mathrm{CE}$, com intuito de sistematizar o registro e a análise das manifestações patológicas em fachadas. A edificação selecionada foi baseada no seguinte critério: realização do laudo de inspeção predial, em seguida, o teste de percussão em fachadas; domínio do revestimento cerâmico nas fachadas; apresentar manifestações patológicas aparentes nas fachadas; viabilizar o acesso ao edifício e permitir a divulgação dos dados. Portanto, a metodologia do estudo (imagem 01) iniciou a partir da realização de um laudo técnico de inspeção predial, que serviu como base de dados para entender como se apresentava o comportamento da fachada, após isso, foi realizado uma inspeção visual na fachada e assim proposto a realização do ensaio não destrutivo, o teste de percussão, em seguida, análise dos dados.

Imagem 01: Metodologia do estudo.

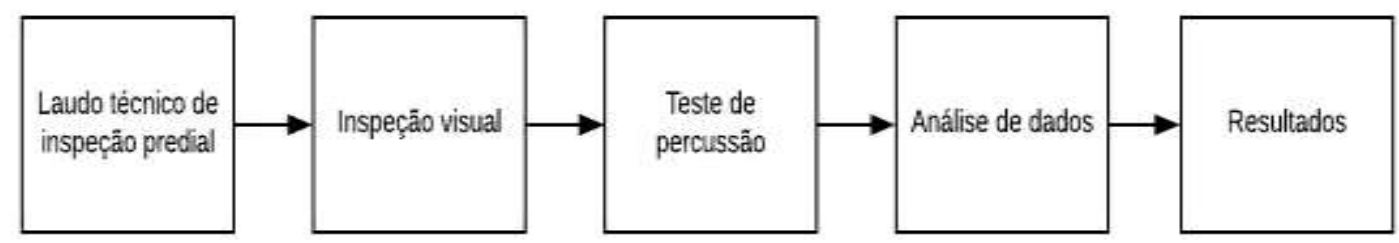


Fonte: Autoria própria (2019).

Visando salientar a compreensão do tema por meio do estudo de caso, a edificação escolhida foi de uso residencial no município de Fortaleza, Ceará, o qual possui como logradouro a Rua Joaquim Nabuco- Praia de Iracema. O edifício residencial possui onze pavimentos, um subsolo, guarita com eclusa, casa de gás, hall/recepção, circulação, elevador social, elevador de serviço, escada de segurança, quarto de zelador, W.C./zelador, salão de festas, copa, W.C. masculino e W.C. Feminino. A edificação é estruturada em pilares, vigas e lajes.

A respeito das diretrizes para a vistoria e estruturação e elaboração do laudo de inspeção predial, tomou-se como critério as etapas sugeridas pelo IBAPE, devido a sua relevância dentro do ramo da engenharia diagnóstica, e, principalmente, pelo fato de que nela se sugere enquadrar perfeitamente às exigências da lei vigente na cidade de Fortaleza, Ceará.

Com relação ao teste de percussão, foram exercidas aproximadamente dez visitas ao local, com intuito da realização do mapeamento da edificação, relatório fotográfico e acompanhamento do serviço. Os trabalhos foram iniciados com inspeção visual, por meio de descidas com balancins individuais tipo "cadeirinha", desde a cobertura até o pavimento térreo, de forma a abranger toda a área das fachadas, e através do registro fotográfico, permitiu uma avaliação do estado de conservação geral da edificação e uma pré-análise das patologias existentes. Ainda assim, possibilitou um mapeamento das áreas com som cavo e, portanto, com prováveis problemas de aderência.

\section{RESULTADOS}

A imagem abaixo representa o mapeamento da fachada Norte, podendo-se observar uma grande área com desplacamento e/ou descolamento cerâmico, bem como ausência de rejunte, sendo representado com formato quadricular e circular, respectivamente, em todas as vistas das fachadas da edificação. Portanto, foi realizado um mapeamento nas fachadas com o auxílio da tinta branca a base d'água para fazer as marcações para melhor identificar as manifestações patológicas existentes, com formato quadricular foram os desplacamentos e/ou descolamentos do revestimento cerâmico e formato circular a ausência de rejunte.

Dessa forma, foram coletados os seguintes dados: área total de cerâmicas das fachadas, área com descolamento e falta de rejunte. 
Apontando o mapeamento da fachada mostrado acima, tem-se como resultado a fachada Norte uma área total de aproximadamente $617,96 \mathrm{~m}^{2}$ em revestimento cerâmico, onde 49,62 $\mathrm{m}^{2}$, que representa $8 \%$ da área total da fachada, corresponde ao desplacamento cerâmico e $18,89 \mathrm{~m}^{2}$, ou seja, $3 \%$, corresponde a falta de rejunte.

De acordo com a imagem 03, conclui que a fachada Sul tem uma área total de aproximadamente $638,21 \mathrm{~m}^{2} \mathrm{em}$ revestimento cerâmico, onde $29,72 \mathrm{~m}^{2}$, que representa $5 \%$ da área total da fachada, corresponde ao desplacamento cerâmico e $62,93 \mathrm{~m}^{2}$, ou seja, $10 \%$, corresponde a falta de rejunte.

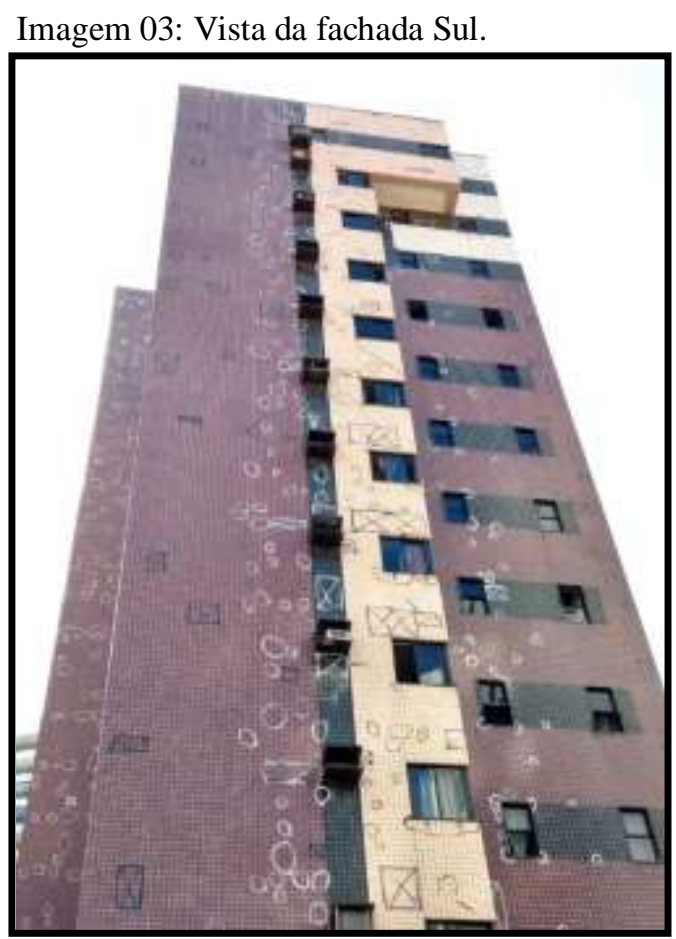

Fonte: Autoria própria (2019).

Baseado na imagem 04, a fachada Leste tem uma área total de aproximadamente $1665 \mathrm{~m}^{2}$ em revestimento cerâmico, onde $62,01 \mathrm{~m}^{2}$, que representa $6 \%$ da área total da fachada, corresponde ao desplacamento cerâmico e $34,53 \mathrm{~m}^{2}$, ou seja, $3 \%$, corresponde a falta de rejunte. 
Imagem 04: Vista da fachada Leste.

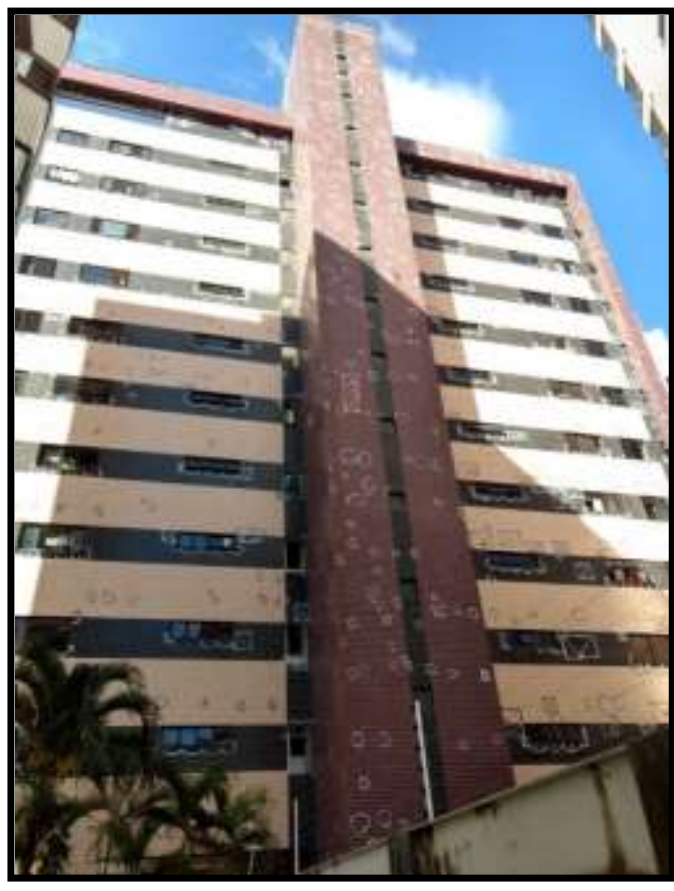

Fonte: Autoria própria (2019).

Imagem 05: Vista da fachada Oeste.

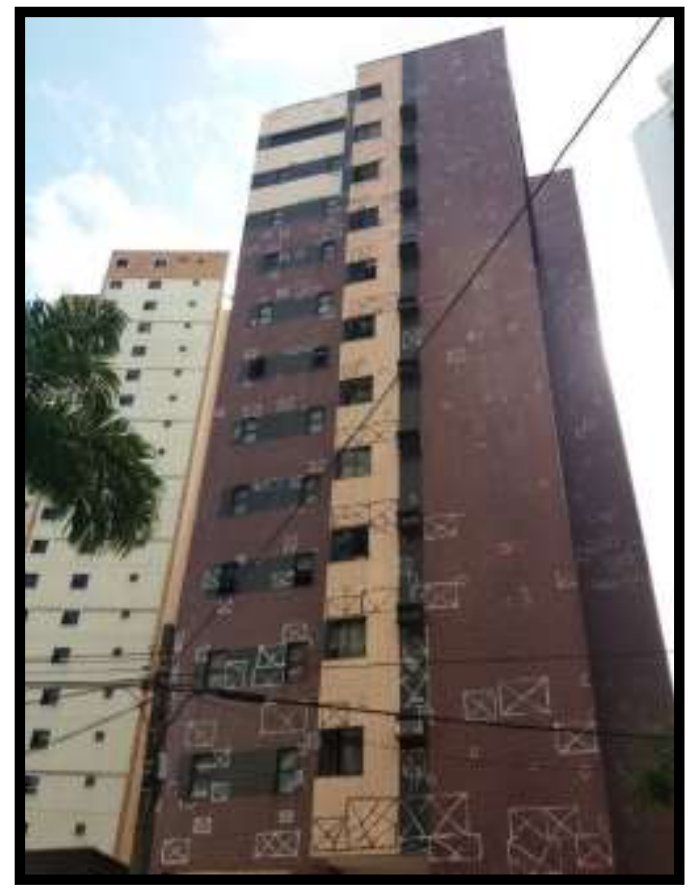

Fonte: Autoria própria (2019).

Conforme o mapeamento acima (imagem 05), a fachada Oeste tem uma área total de aproximadamente $1226,37 \mathrm{~m}^{2} \mathrm{em}$ revestimento cerâmico, onde $47,07 \mathrm{~m}^{2}$, que representa $4 \%$ da área total da fachada, corresponde ao desplacamento cerâmico e 86,32 $\mathrm{m}^{2}$, ou seja, 7\%, corresponde a falta de rejunte. Somando-se as áreas das 4 fachadas, temos um total de 
$3647,54 \mathrm{~m}^{2}$ de revestimento cerâmico, onde $188,42 \mathrm{~m}^{2}$, ou seja $5 \%$, corresponde ao revestimento desplacando, e 202,67 $\mathrm{m}^{2}, 6 \%$, a falta de rejunte.

O estudo de caso vem auxiliar na formação do engenheiro de como proceder em meio às atividades de inspeção predial e manifestações patológicas observadas em fachadas, assim como a causa do problema e sua intervenção, uma vez que os conceitos abordados e análises feitas objetivam auxiliar e intervir na tomada de decisões de um caso real sobre as medidas que se devem tomar, como também expor a importância das atividades de manutenção predial para a conservação da edificação.

Contudo, as representações das fachadas realizadas no programa computacional tiveram o intuito de mostrar detalhadamente as manifestações patológicas em cada local do revestimento da fachada, facilitando que o engenheiro.

\section{CONCLUSÃO}

Após toda análise das fachadas, foi elaborado um laudo do teste de percussão, este entregue ao síndico, resultante das áreas das 4 fachadas, totalizando em $3647,54 \mathrm{~m}^{2}$ de revestimento cerâmico, onde $188,42 \mathrm{~m}^{2}$, ou seja $5 \%$, corresponde ao revestimento desplacando, e $202,67 \mathrm{~m}^{2}, 6 \%$, a falta de rejunte.

Nesse contexto, de acordo com os dados obtidos acerca do revestimento cerâmico, destaca-se a importância da troca desse material danificado que está oferecendo riscos aos moradores, ressaltando que a retirada das cerâmicas danificadas, poderá ocasionar, ainda, o descolamento do revestimento ao lado.

Dessa forma, o valor em porcentagem do revestimento deve ser majorado, pois, na retirada desse material poderá haver o desplacamento de outras cerâmicas. Portanto, visando a garantia de um serviço com segurança, a contratação de um profissional habilitado verifica-se de extrema importância para avaliar, detalhadamente, os eventuais riscos que a estrutura esteja a apresentar.

\section{AGRADECIMENTOS}

Agradecemos a empresa SOARES ENGENHARIA, pelo o apoio e oportunidade em permititir a realização deste trabalho.

\section{REFERÊNCIAS}

ALBUQUERQUE, A. T.; OTOCH, S. Proposta de classificação da agressividade do ambiente na cidade de Fortaleza. Olinda: CONGRESSO BRASILEIRO DO CONCRETO, 2005.

ALVES, SCHARLETT O.'HARA CHRISTYANE. Elaboração de minuta de um projeto de lei relacionada à inspeção e manutenção predial de edificações para o município de Anápolis. 2018.

A.S. Barbosa, "Estudo numérico-computacional e analítico do choque térmico em fachadas de edificações", Diss. Mestr., UnB, Brasília (2013).

ASSOCIAÇÃO BRASILEIRA DE NORMAS TÉCNICAS. NBR 5410: Instalações elétricas de baixa tensão. Rio de Janeiro, 2004.

NBR 5674: Manutenção de edificações - Requisitos para o sistema de gestão de Manutenção. Rio de Janeiro, 2012.

BOTELHO, A. M. F.; FERREIRA, L. Q. Proposta de elaboração de laudo de inspeção predial em áreas comuns de uma edificação residencial de múltiplos pavimentos- Estudo de caso no DF. Universidade Católica de Brasília, 2015.

BRANCO, L. A. M. N.; NEVES, D. R. R. Estratégia de inspeção predial. Belo Horizonte: FUMEC, 2009.

BRASIL. Lei n. 9913, de 16 de jul. de 2012. Obrigatoriedade da Vistoria Técnica, Manutenção Preventiva e Periódica das Edificações e Equipamentos Públicos ou Privados no Âmbito do Município de Fortaleza, e das outras Providências. Art. 3º Fortaleza, CE, jul 2012. 
BRITO, T. F. Análise de manifestações patológicas na construção civil pelo método GUT: Estudo de caso em uma instituição pública de ensino superior. João Pessoa: UFPB, 2017.

CAMPOS, Douglas Tadeu Ansolin; AUDITORIA, Avaliações. Plano de inspeção predial em sistemas de segurança contra incêndio em edificações residenciais multifamiliares. Revista Especialize On-line IPOG, v. 6, n. 1, p. 21, 2012.

CONSELHO FEDERAL DE ENGENHARIA, ARQUITETURA E AGRONOMIA. Resolução No 2018 de 29 de junho de 1973. Rio Grande do Norte, 2013.

GIL, A. C. Métodos e Técnicas de Pesquisa Social. 5 ed. São Paulo: Atlas, 2007.

GOMIDE, Tito; PUJADAS, Flávia, NETO, Jerônimo. Técnicas de Inspeção e Manutenção Predial, ed. Pini. São Paulo, 2006.

GRIMM, C. T. Research Needs for Aging Masonry, 2000. Disponível em http://scitation.aip.org/getabs/servlet/GetabsServlet?prog=normal\&id=ASCECP000109040

558000128000001\&idtype=cvips\&gifs=Yes. Acessado em 11/10/2019.

J.G. Uliana, A.F.O. Falcão, R.B. Soares, R.N. Maioli, G.L. Vieira, in $1^{\circ}$ Congr. Bras. Patologia Constr., Foz do Iguaçu (2014).

KALIL, M.L; FRANCISCO, V. P.; PUJADAS, F. Z. A.; SILVA, G. V. Cartilha de inspeção predial a saúde dos edifícios. São Paulo: IBAPE SP, 2012.

LIMA, F.S; OLIVEIRA, J.C; LOPES, W.R. Manutenção predial e suas influências diretas sobre anomalias apresentadas. Trabalho de Conclusão de Curso -Universidade Estácio de Sá, Rio de Janeiro, 2016.

MATTOS JÚNIOR, Amarilio da Silva; BRITTO, Luiz Vinicius Araujo; SOUZA, Ingrid Ferreira; ALVES, Octavio Alberto de Aragão Dantas. Inspeção predial - Descompasso entre legislação e prática. In: XIX Congresso Brasileiro de Engenharia de Avaliações e Perícias. Foz do Iguaçu. 2017.

MUNHOZ DE MOURA, Guilherme Henrique et al. Diretrizes, roteiro e proposta de laudo para inspeções prediais. 2017.

NEVES, Daniel Rodrigues Rezende; BRANCO, Luiz Antônio MN. Estratégia de inspeção predial. CONSTRUINDO, v. 1, n. 01, 2009.

NEVES, Y. T.; CLAUDINO, C. M. A., DINIZ, M. I. L., SENA, T. S. Análise de manifestações patológicas presentes em escolas públicas. Conferência Nacional de Patologia e Recuperação de Estruturas. Recife, 2017.

OLIVEIRA, C. S. P., SILVA FILHO, L. C. P. Discussão do papel das leis de inspeção como suporte para a adoção de estratégias de manutenção preventiva. In: CONGRESSO BRASILEIRO DO CONCRETO CBC50, 50 ${ }^{\circ}, 2008$, Salvador. Anais... IBRACON: Salvador, 2008.

OLIVEIRA, ROGÉRIO FREITAS. Monografia: Conceitos, procedimentos, atribuições e competências do profissional de Engenharia Legal. Belo Horizonte, 2009.

PACHECO, L. S. et al. Leis de marquises e elementos em balanço: o início do pensar em inspeção predial. In: Congresso Brasileiro do Concreto. 2014.

PUJADAS, Flávia Zoéga Andreatta. Inspeção Predial-Ferramenta de Avaliação da Manutenção. In: XXIII Congresso Panamericano de Valuación. São Paulo. 2007.

SILVA, Geraldo Oliveira da. Proposta de metodologia de manutenção predial. 2014.

SILVA, WLADSON LIVRAMENTO. Inspeção predial: diretrizes, roteiro e modelo de laudo para inspeções em edificações residenciais da cidade do Rio de Janeiro. / Wladson Livramento Silva - Rio de Janeiro: UFRJ/ESCOLA POLITÉCNICA, 2016. 


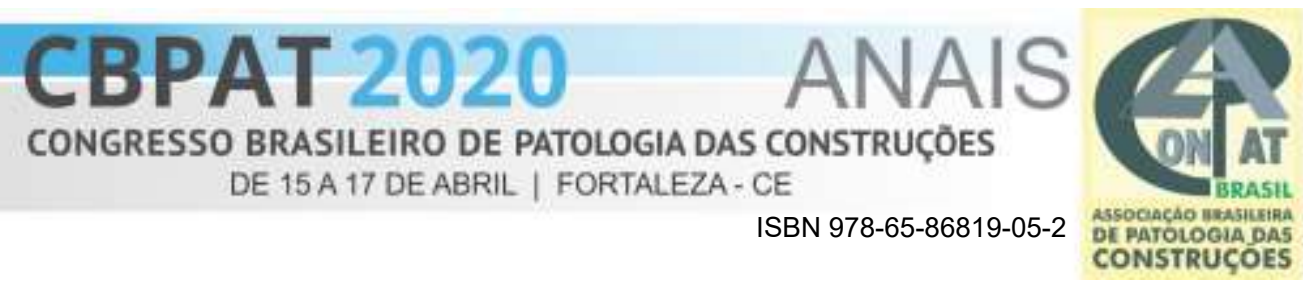

Y.F.M. Moscoso, "Estudo numérico e experimental das tensões atuantes na argamassa colante de fachadas de edificações sob ação da fadiga termomecânica”, Diss. Mestr., UnB, Brasília (2013). 